\title{
Wooden Fishing Vessel Building at Samut Sakhon: Its Last Breath
}

\author{
Budsaba Kanoksilapatham
}

\begin{abstract}
This research aims at presenting the historical accounts and the procedural steps reflecting local wisdom regarding the building of wooden fishing vessels at Samut Sakhon Province, Thailand. With help from community members, a list of interviewees was identified; a set of interview questions was constructed. Next, in-depth interviews and non-participant observation were conducted with remarks noted relating to the surrounding context. Finally, a focus group discussion was held to exchange opinions and verify the interview accounts. The study reveals that the guru of fishing vessel building is a Chinese Hainanese man who owned the first shipyard in Samut Sakhon Province about 100 years ago. The guru and other masters of wooden fishing vessel building contributed to strengthening this local wisdom knowledge. Without explicit instruction from the guru, these masters were able to acquire and sharpen their expertise at this shipyard "through the back door" using avid observation. Samut Sakhon vessels are uniquely known to be strong in construction and graceful in design. This local wisdom has never been recorded, but it is systematic, consisting of multiple steps. However, this building business went into decline, resulting in the closedown of the shipyards one after another. The last closure about ten years ago led to an end of wooden fishing vessel building. This study represents a record of this local wisdom to shed light on the community roots and disseminate it to the next generation to study, appreciate, and integrate it with classroom learning.
\end{abstract}

Index Terms-Building, fishing vessel, Samut Sakhon, wooden.

\section{INTRODUCTION}

Currently, every nation is undergoing changes at a fast pace, be they in economics, society, technology, or communication. One of the unpleasant consequences is that wisdom, technology, and culture pertaining to specific communities can disappear overnight if no preventative measures are systematically devised and concretely implemented. Therefore, at present, every sector of a nation, be it public or private, has been increasingly more conscious of the importance of any attempt to maintain, transmit, and revitalize their local wisdom, technology, and culture before it comes to an end.

Thailand is one of the countries with its own cultural characteristics. Thai people's way of life has been closely connected with water, a prominent feature of Thai life. Specifically, Samut Sakhon Province is one of the provinces

Manuscript received November 30, 2015; revised March 1, 2016. This work was supported by the Thai Higher Education Research Promotion (HERP) Grant, Office of the Higher education Commission, Thailand.

Budsaba Kanoksilapatham is with the Department of English, Faculty of Arts, Silpakorn University, Nakhon Pathom, Thailand (e-mail: kanoksib@hotmail.com). with an area connected to the Gulf of Thailand (Fig. 1). In addition, the residents of this province have usually been engaged in activities connected with water. This province is known to have an abundance of industries and businesses, be they large or small, related to fishing.

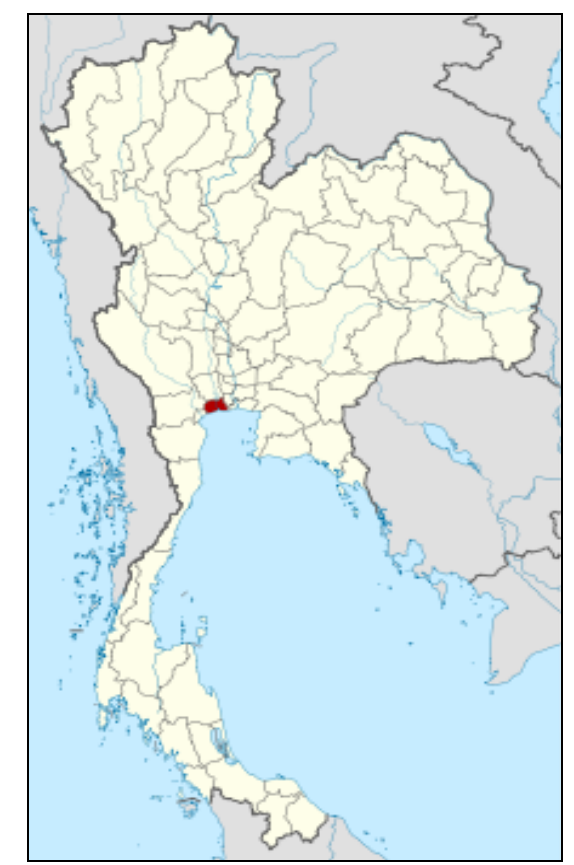

Fig. 1. Location of Samut Sakhon province, Thailand.

Among the number of outstanding provincial features is wooden fishing vessel building. Wooden fishing vessel building is not only considered as one of the features shaping the local residents' way of life but also represents local wisdom that local residents and community members should be proud of, and be conserved for generations to come.

At present, local wisdom of wooden fishing vessel building is menacingly vulnerable to being lost for a myriad of reasons. First and foremost, the number of skillful wooden fishing vessel builders or shipwrights has substantially decreased, resulting in the discontinuity of knowledge transmission. Next, building each wooden fishing vessel requires a number of different expertise and skills, contributing to fragmented knowledge of the fishing vessel construction. Third, wood, which is the major and most important material for building fishing vessels is not available. Coupled with the rapid expansion of the fishing business, fishing vessel owners are compelled to be more interested in using other materials (like iron and fiberglass) that are more easily available. These factors culminate in the decrease and vulnerability of wooden fishing vessels in the near future if no action is taken to preserve the knowledge of constructing the vessels. 
In order to make the management of local wisdom, technology, and culture more effective and efficient, to maintain the unique identity of the Samut Sakhon community, and to enhance the pride and strength of the community, the objectives of this study are twofold: to provide historical accounts of the province that lead to the existence of wooden fishing vessel building and to make explicit the body of knowledge regarding wooden fishing vessel building. It is expected that this study will lend itself as one of the avenues to record, maintain, and disseminate the local wisdom.

\section{CONTEXT: SAMUT SAKHON}

Samut Sakhon, as highlighted in Fig. 1, is in the central part of Thailand. Historically, this community is originally known as Tha Chin, which emerged in the chronicle as an ancient outpost or premise to mobilize soldiers and troops to take part in Burmese battles in the Ayutthaya period [1]. Later on, because of its ideal location, this area was recognized as a hub for trading and welcoming foreigners, especially Chinese people. In the old days, the sight of a great number of commercial junks, especially several Chinese junks docking and stopping to carry out business transactions, was very common. As a result, currently, the logo of this province is a Chinese junk sailing in the sea (Fig. 2).

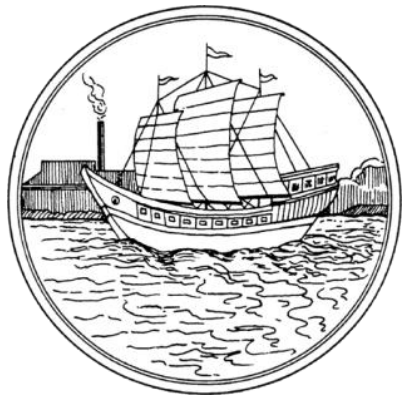

Fig. 2. Logo of the province - A Chinese junk sailing in the sea.

In the reign of King Rama III (1847 or BE. 2390), the name of this community was changed from Tha Chin to Sakhon Buri. In this reign, a group of rebels was formed by Chinese people in this community, which was later suppressed in the year 1897 (BE. 2440) in King Rama V and completely eradicated in King Rama VI. Since then, the Chinese people in this community got together and legally formed a number of associations that still exist nowadays. On March 9, 1946 (BE. 2489), this community was officially enacted as a province in the reign King Rama VIII.

Geographically, Samut Sakhon is one of the provinces in the western region of Thailand, only 30 kilometers from Bangkok and 2 kilometers from the sea. This province is situated on the Gulf of Thailand, with a coastline of about 42 kilometers. The size of the province is relatively small being about 872 square kilometers, with a population of about 510,511 [2]. The province has three administration zones: Mueang, Krathum Baen, and Ban Phaeo. Mueang District is the only administrative zone that has its border on the Gulf of Thailand (Fig. 3). Therefore, the nature of the three zones in Samut Sakhon Province is quite distinct, depicting the diversity of the province.

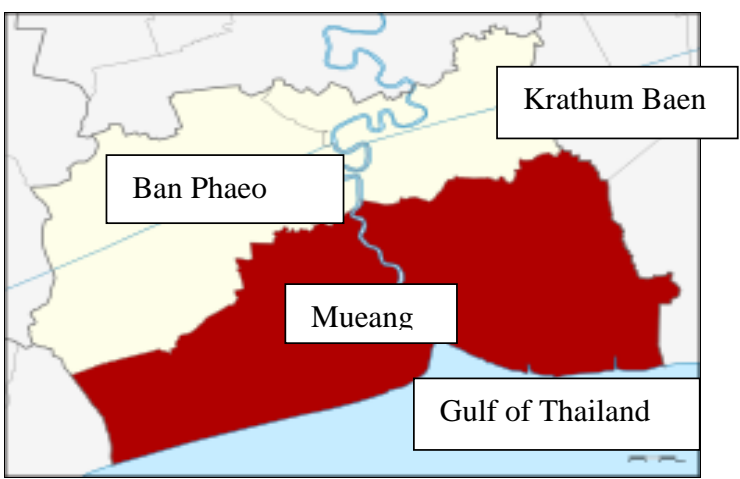

Fig. 3. Highlighted Mueang district of Samut Sakhon.

Based on the historical and geographical accounts described above, two features of Samut Sakhon Province that are relevant to the focus of this study are highlighted. One, it is quite clear that the Chinese people have long been closely connected to this area. Second, the residents of this province have been involved and engaged in activities related to fishing in one way or another. In this regard, the province's location, especially Mueang District near the Gulf of Thailand, allows the fishing vessel builders in this area to be enthusiastic to discover new technology to enhance fishing capacity. Economically, according to the gross provincial product or GPP in year 2013 [3], Samut Sakhon Province had the seventh largest GPP despite its small size compared with the other provinces in Thailand. At present, Samut Sakhon Province has a high capacity of fishing, with a great volume of fish hauls, serving a basis for other related fishing businesses including selling and buying fish hauls and fishing haul processing, preserving, and exporting.

\section{METHODS}

\section{A. Data Collection}

This study opted to use in-depth interviews as a means to elicit information related to wooden fishing vessel building. First, a list of interviewees was made. Local residents, especially those who at the time of study performed or were involved in activities related to fishing vessel building such as fishing vessel owners, dockyard owners, and fishing vessel engine suppliers, were asked to nominate individuals whom they believed were the masters of wooden fishing vessel building, be they alive or dead. Subsequently, if possible, these nominated individuals were interviewed.

A set of questions was constructed to elicit more information about fishing vessel building during in-depth interviews. The questions were derived from the study of documents available from different sources, covering the historical perspective, constructional materials and instruments, procedural steps in the building, and other additional perspectives that would contribute to a more complete picture of the questions addressed [4].

Upon the completion of the interviewee list and the question set, the researcher conducted in-depth interviews with the persons nominated by the community members. With the permission from the interviewees, the interviews were recorded. While the interview was taking place, the researcher observed, recorded, took notes and pictures of the 
interviewees, living quarters, and decor, to elicit additional information to complement the interview data and to estimate the situations related to fishing vessel building. This procedure is also known as "non-participant observation," which allows the researcher to understand the situation of wooden fishing vessel building by entering a community in focus, without taking an active part in the situation under investigation [5]

Finally, the researcher organized a focus group discussion for interviewees and other people who are involved in other businesses related to fishing, so that all of these people could exchange ideas and opinions and help verify the interview accounts related to fishing vessel building. This approach allows the researcher to gather people from similar backgrounds or experiences (in wooden fishing vessel building, for this study) to discuss a topic of interest (wooden fishing vessel building) as naturally as possible among themselves, with the researcher as a moderator [6].

\section{B. Data Analysis}

The data collected from interviews, non-participant observation, and a focus group discussion were analyzed and categorized into sections such as historical accounts, materials, instruments, procedures, rituals related to the building, development, and factors contributing to the demise of this business.

\section{Results}

Based on the data obtained from triangulation, the findings are divided into two major sections. The first section presents the accounts of the gurus and the nine masters of wooden fishing vessel building. The second section of the findings describes the tools, materials, and procedural steps typically followed in the building of wooden fishing vessels.

\section{A. Gurus and Masters of Wooden Fishing Vessel Building in Samut Sakhon Province}

Based on the input from the local residents, especially those who at the time of study performed or were involved in activities related to fishing vessel building such as fishing vessel owners, dockyard owners, and fishing vessel suppliers, 14 individuals were nominated to be experts of wooden fishing vessel building in Samut Sakhon Province. Four on the list passed away, leaving ten individuals to be interviewed by the researcher. Details of these experts are presented in 4.1 , and those of wooden fishing vessel building procedures are presented in 4.2.

Based on the collected data, Mr. Hong Yi Sae Wang and Mr. Hong Dek Sae Wang, two brothers, migrated to Samut Sakhon, Thailand when Japanese soldiers invaded Hainan Island. At Samut Samkhon, they were both engaged in repairing fishing vessels. Later, Mr. Hong Yi Sae Wang went back to Hainan Island, whereas Mr. Hong Dek Sae Wang and his two sons, Mr. Kheng Hiang and Mr. Kheng Sang, remained in Thailand. Little information is known about $\mathrm{Mr}$. Hong Dek, but according to the data, Mr. Kheng Hiang and Mr. Kheng Sang have been recognized as two gurus of building wooden fishing vessels in Samut Sakhon and Samut Prakarn, respectively. In short, the local wisdom of building wooden fishing vessels has been transmitted from one generation to the next, going back about 100 years.

Mr. Kheng Hiang Sae Wang (BE. 2452-2536), a guru of wooden fishing vessel building in Samut Sakhon, set up his shipyard business, the first of its kind in this province at Mueang District. Starting from building towboats, he later began to build wooden fishing vessels larger in size and scale as construction technology became more advanced. Meanwhile, Mr. Kheng Sang Sae Wang (BE. 2456-2548), Mr. Kheng Hiang's younger brother, is a guru of fishing vessel in Samut Prakan. After spending some time in Samut Sakhon and Samut Songkhram, Mr. Kheng Sang finally established his fishing vessel building business and a shipyard in Samut Prakan Province. His expertise in building fishing vessels was recognized by the government sector, and his shipyard has become a site to welcome national and international scholars and visitors.

At this juncture, Mr. Kheng Hiang, a guru of fishing vessel building particularly in Samut Sakhon, had generated a large number of fishing vessel builders or shipwrights who later on, in their own ways, shaped the future of fishing vessel building in this province. Mr. Kheng Hiang's fishing vessel building business prospered tremendously, attracting the interest of the local residents of Samut Sakhon and relatives migrating from Hainan Island. Therefore, these people became apprentices at Mr. Kheng Hiang's shipyard.

In fact, all of the fishing vessel builders or masters interviewed in this study had been apprentices for a period of time at Mr. Kheng Hiang's shipyard. These individuals are: Mr. Poh Sai Sae Bang (BE. 2469-2556), Mr. Tum Manichote (BE. 2469-2550), Mr. Ki Yao Sae Lim, Mr. Suwan Warichai, Mr. Chawan Ratanaphutthasakhon, Mr. Mr Angkhan Thirananthraphon, Mr. Pramot Butsayamongkhon, Mr. Aphichat Phaisombun, Mr. Bunchuay Sae Phu, Mr. Bunsit Khamprasert, Mr. Homchan Phaisombun, and Mr. Chakhrit Chalartphraek. The last ten of these names served as our interviewees for this study.

Embarking upon the career of a fishing vessel builder at Mr. Kheng Hiang's school of wooden fishing vessel building, the masters were neither systematically nor explicitly taught how to build a fishing vessel. In other words, these individuals learned how to build a fishing vessel "through the back door," i.e., from being an apprentice of the guru, Mr. Kheng Hiang Sae Wang. However, with the implicit knowledge and hands-on experience gained at Mr. Kheng Hiang's shipyard, these masters of fishing vessel building have constructed hundreds of fishing vessels that have fed the community of Samut Sakhon for an extended period of time.

Regarding the profiles of the masters of wooden fishing vessel construction, their age ranges from 47 to 92 years old at the time of research. As for their educational background, one of them migrated from Hainan Island to Thailand when he was young and thus did not have a chance to receive formal education. Six of them completed grade level 4, and two grade levels 6 and 7, respectively. One of them completed high school. The interview session lasted from 90 to 120 minutes. These masters were interested in fishing vessel building for different reasons. Some of them were in this business because of the influence from their family members or relatives who had previously been in this 
business. The others fell in love with the beauty of woodwork which inspired them to be fishing vessel builders. For example, first, Mr. Lu Sai Sae Bang, a nephew of Mr. Kheng Hiang, was known to be so meticulous in his vessel building that two pieces of wood of the hull were placed with such a tiny gap that no caulk was virtually needed. In addition, without any formal education, he managed to calculate the volume of the wood. Next, Mr. Angkhan Thirananthraphon, who also had previous work experience at Mr. Kheng Hiang's school, was able to acquire the expertise of building vessels and display his creativities. For instance, the vessels constructed by him bear the signature of having an elaborate deckhouse. Third, Mr. Homchan Phaisombun, 50 years old, spent his time at Mr. Kheng Hiang's school too and started his building business when he was only 20 years old. The youngest master of the interviewees was 47 years old, and with the technique of "learning through the back door," he finally established his fishing vessel building business and has built more than 20 fishing vessels.

In short, Mr. Kheng Hiang's school of building fishing vessels has produced a number of masters who have not only continued the building activities but also developed the field forward by adding creativity and shaping the future of vessel building to their utmost abilities.

\section{B. Building Wooden Fishing Vessels}

This section presents the accounts relating to the essential materials, instruments, and the procedural steps of building wooden fishing vessels.

\section{1) Building materials and tools}

Wood is evidently the most important materials for building wooden fishing vessels. The collected data revealed that, originally, the wood popularly used to build different parts of the fishing vessels are teak wood, hopea adorata wood, wood or rosewood, and xylia kerrii craib wood or iron wood. The selection of wood for fishing vessel construction depends primarily on the fishing vessel owners' budget. Piles of wood waiting to be used (Fig. 4) indicate their crucial role and substantial demand for this business.

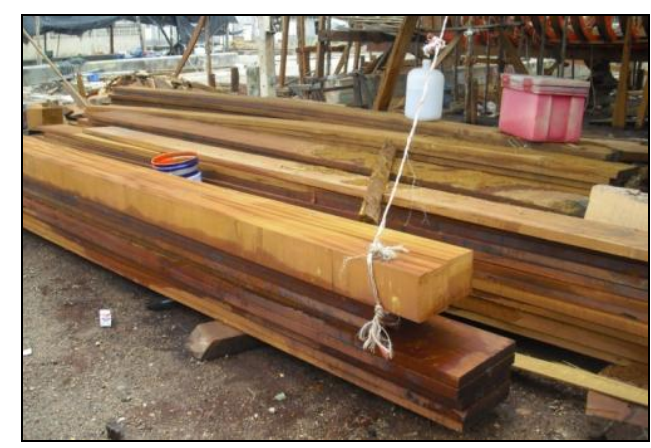

Fig. 4. Piles of wood used for fishing vessel construction.

Teak wood is known to be ideal for fishing vessel building, but it is quite scarce and expensive. Fishing vessel builders thus decide to use hopea adorata wood and padauk wood for the construction instead. Each wood type has its own characteristics and properties. For instance, hopea adorata wood is durable in the water, and thus is chosen to build different parts of the fishing vessels especially those immersed in the water - the hull of the vessel and the frames.
Hopea adorata wood coated with paint makes it even more durable. That is, shipworms, a species of small size saltwater clam notorious for boring the vessel parts immersed in the water, cannot do any damage to hopea adorata wood. Another positive characteristic of hopea adorata wood is that, when exposed to the heat released from the pressure stove (a device releasing the heat), it easily adjusts conforming to the designed shape of the vessel, without breaking.

Padauk wood or rosewood is another popular wood type for fishing vessel construction, especially for the parts that are difficult to repair, including the stem, keel, sternpost, and deckhouse. Padauk wood is heat-resistant so it is fit for the fishing vessel parts that are exposed to the sun. If covered, padauk wood will easily rot. Similar to hopea adorata wood, padauk wood is increasingly higher in price and smaller in size, thus not fit for fishing vessel construction.

Satisfactory wood materials are generally getting scarce for fishing vessel construction due to a number of reasons. Those who ran lumber businesses could not find the wood materials to satisfy fishing vessel builders' needs, leading to the decline of the quality of the fishing vessels. In short, the traditional use of hopea adorata wood or padauk wood or rosewood is no longer feasible and practical. Subsequently, fishing vessel builders turn to other wood types instead.

As for the tools and materials used for fishing vessel construction, some of the common ones include nails, bolts, and nuts. In the old days, the device that held the planking and the ribs together was Luk Pra Sak or wooden bolts (Fig. 5 ). Wooden bolts are usually made of cassia garrettiana craib wood, and sometimes of hopea adorata wood or padauk wood. Wooden bolts represent traditional local wisdom, with the unique characteristic of not easily rotting when exposed to sea water. Typically, a wooden bolt has a bigger head, compared with the body of the bolt. Similar to a regular bolt, a wooden bolt is clinched into a hole in the wood made earlier, holding planking in its place. To make sure that a wooden bolt performs its best function of holding wood pieces together, a wooden wedge is inserted to the end of the wooden bolt which is previously split to keep the wooden bolt in its place for an extended period of time. Wooden bolts thus represent fishing vessel builders' local wisdom. In fact, these wooden bolts were popular and advantageous because metal bolts and nails can get rusty when exposed to sea water. However, producing one wooden nail is quite time consuming and labor intensive.

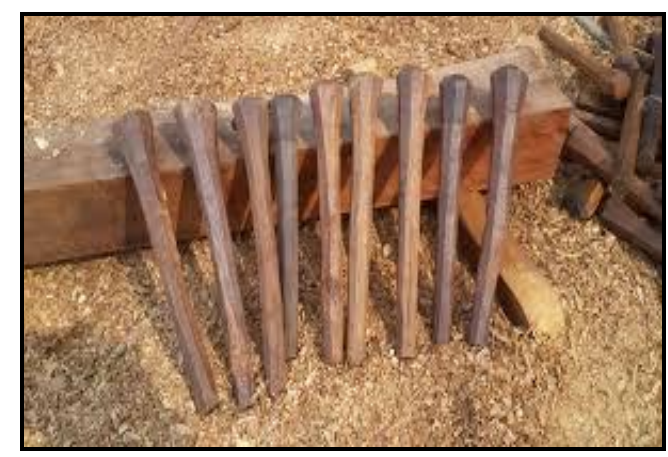

Fig. 5. Wooden bolts.

Other building materials that are important in fishing vessel construction are those used to prevent water from 
leaking into a fishing vessel. These materials include cotton yarn, dammar, wood oil, and caulk. For example, caulk is derived from bark, beaten to shreds, and dipped in wood oil. Caulk is forced into the gap between the planking to prevent water from leaking in. Other materials to make a fishing vessel beautiful and functional are, for example, paint, fishing gear, and fishing vessel engines.

In the process of building a fishing vessel, other tools are also required including plane (Fig. 6), bench vise, axe, metal hammer, try square, buzz saw, pressure stove, hand saw, plumb bob, chisel, etc. Some of these tools are no longer used these days, and are replaced by electrical appliances such as an electric saw, drill, pulley, jack, and crane. The introduction of electrical appliances allows the construction work to be completed in a short time, and it is also less dangerous.

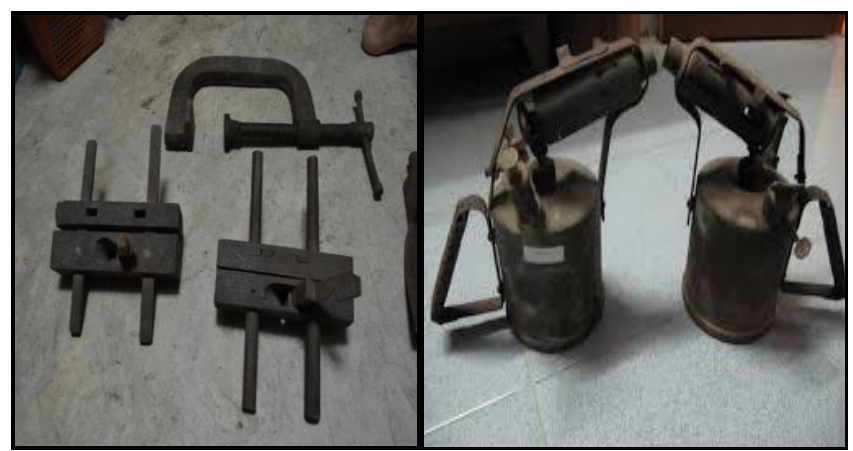

Fig. 6. Planes and bench vise (left), and pressure stoves (right).

\section{2) Building procedures}

Despite the absence of a written record of fishing vessel building and formal lessons focusing on fishing vessel building, the process of building a vessel is quite systematic with one step after another, when the stock of wood and the required tools are available. However, with the availability of manpower and advanced technology, a number of fishing vessel building steps can be concurrently taken. The following section presents the principal steps of building vessels reflecting sequential procedural steps that these masters traditionally follow.

\section{Specify the Size of a Fishing Vessel}

Initially, based on the vessel owner's decision and financial allocation, the length and the width of the vessel are specified. The length of the vessel refers to the measurement from the most extended point of the vessel at the front (the prow) to the most extended point of the sternpost of the vessel. The width of the vessel is determined by the curve of a set of frames or ribs of the vessel (to be described later). In some cases, the size of the vessel is generally governed by the expected storage capacity of freezing rooms and fish hauls.

\section{Lay the Keel or bar Keel}

The keel is a large and strong centerline piece of wood along the length of the fishing vessel (Fig. 7). It performs the function of the backbone of the vessel. Originally, the keel was made of padauk wood only. Then, hopea adorata wood was used instead because padauk wood was not easily available. Often times, padauk wood is not big or long enough to adequately serve as the keel of the vessel. Laying the keel is a very important step of the construction, and thus it must be carefully laid to make sure that the keel is straight and right in the center of the vessel.

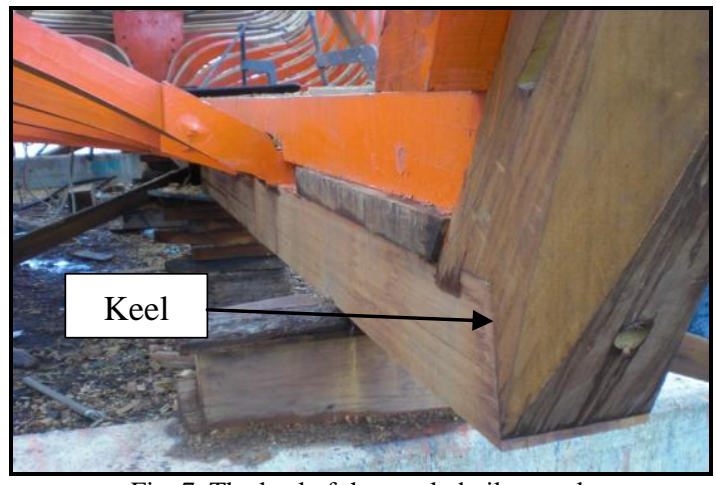

Fig. 7. The keel of the newly built vessel.

\section{E. Set up the Stem}

After the keel is laid, the stem is set up. The stem is a piece of wood connected to the keel, projecting up into the air. This part is usually made of padauk wood and is believed to be inhabited by the vessel Goddess. Usually, in a ritual performed to set up the stem, foods and desserts are offered to the Goddess (Fig. 8). In certain cases, this ritual can be quite elaborate including putting some gold in the holes dug into the top of the stem. Some opt to drill three holes to insert gold, silver, and naga. Nowadays, people might opt to use gold leaves instead. Offerings usually include food, a garland, and three pieces of brightly colored silk fabric to tie around the top of the stem. The food offered to the Goddess usually includes a pig head, duck, and chicken. Fruits commonly used to offer to the Goddess are bananas, jackfruit, young coconuts, oranges, and Chinese cakes (red and white stuffed dough balls). Some offer a large bouquet of flowers, incense sticks, candles, and nine baht in coins. Some people include fire crackers. As far as the setting up of the stem is concerned, a pulley is used to attach the stem to the keel at an auspicious moment. Normally, nine holes are made for nine bolts to keep these two big pieces of wood together. The ninth bot is usually tightened or clinched by the owner of the vessel, marking the auspicious moment of the ritual.

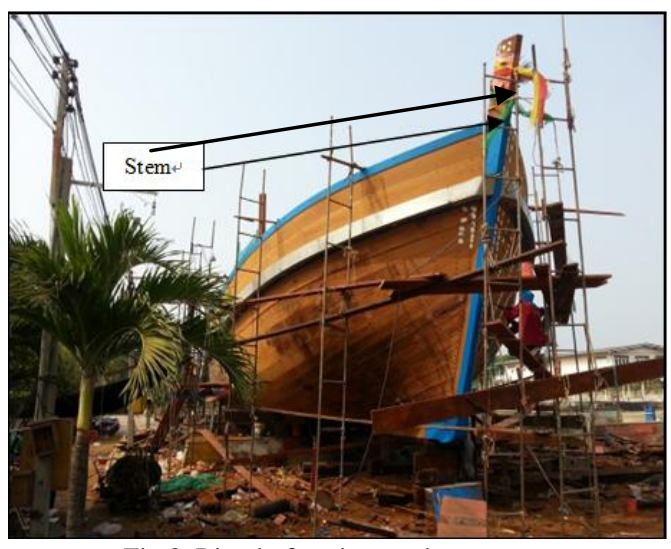

Fig.8. Ritual of setting up the stem.

\section{F. Placing the Deadwood}

The deadwood, the lower part and the other end of a fishing vessel, is one of the most important parts of the vessel. 
It is a thick solid piece of wood (much thicker than the keel and much shorter in length) placed on the keel abaft the vessel. Then, one long piece of wood is placed on each side of the deadwood, forming the slope sternposts abaft the vessel. The deadwood is also the area where the propeller and the stern tube are located, determining the motion and the speed of the vessel when out fishing. Therefore, the deadwood must be very strong to support the vessel.

\section{G. Carving the Frames or Ribs}

Frames or ribs are pieces of thick wood that form the skeleton, shaping and strengthening the vessel. The size of the vessel determines how many pieces of frames are needed (Fig. 9). Usually, a large vessel can have as many as 30-32 ribs or frames whereas a medium one has about 26-28 ribs, and a small vessel has about 23 ribs. Each piece of frame or rib is carved out from a bigger piece of wood, a very initial and crucial stage of fishing vessels that requires expertise and skills. As a matter of fact, of a set of frames, individual frames are distinct with different curves and angles forming the shape of the vessel. The task of designing a set of frames serving as templates for each vessel is invaluable, and thus a set of frames can be sold for a large amount of money. This body of knowledge is not usually shared. If shared, it is for family members only. These masters, based on the interviews, were thus not explicitly instructed on how to create the frame templates. However, due to the importance of the ability to create the frame templates and the tradition not to share this knowledge with others, many builders ended up spending extended years of observation and experience implicitly learning this skill.

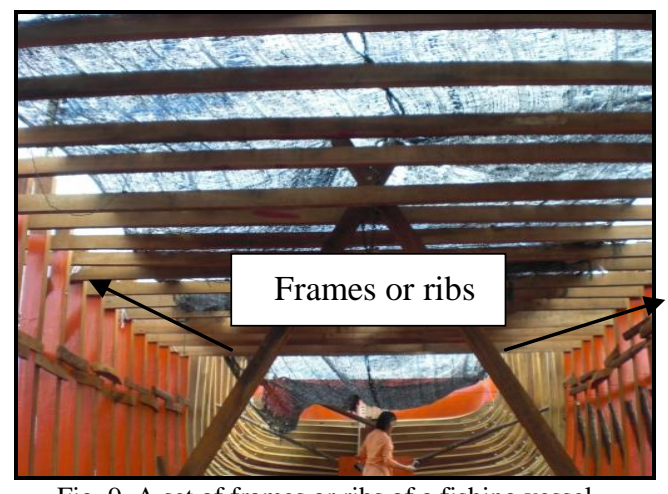

Fig. 9. A set of frames or ribs of a fishing vessel.

Upon the completion of designing a set of frames, individual frames of different sizes are traced onto a piece of plywood or hardboard or rubber wood to produce an entire set of templates. Subsequently, a set of actual frames needed for each vessel is generated by copying the templates onto pieces of wood. Since each vessel may have as many 30 frames, to avoid possible confusion and to make sure that the skeleton of the vessel is accurately balanced, they are numbered and vertically placed at the points marked previously from one end of the keel to the other. Because it is possible that the ribs that are placed on the keel might shift due to its size and weight, another piece of wood is used to horizontally hold the two ends of the ribs together and to keep the rib in its place. In short, the strength of the vessel is determined by the builder's local wisdom, skills, and expertise in carefully creating and designing each frame.

\section{Placing the keelson}

After the ribs or frames are placed at different positions along the keel, another big piece of wood called the keelson is placed right on top and along the keel and above the transverse frames. The keelson is tightened to the keel using a number of bolts and nuts. This piece of wood performs the function of strengthening the keel. In parallel with the keelson, there are two long pieces of wood that are placed across the ribs from the stem to the sternpost. These two pieces of wood are called side keelsons (Fig. 10). They are not as long as the keel and the keelsons. As the name implies, the side keelsons are placed at the bottom of the vessel on the left and right sides of the keel and the keelson in order to keep the ribs in their place, making the vessel even stronger.

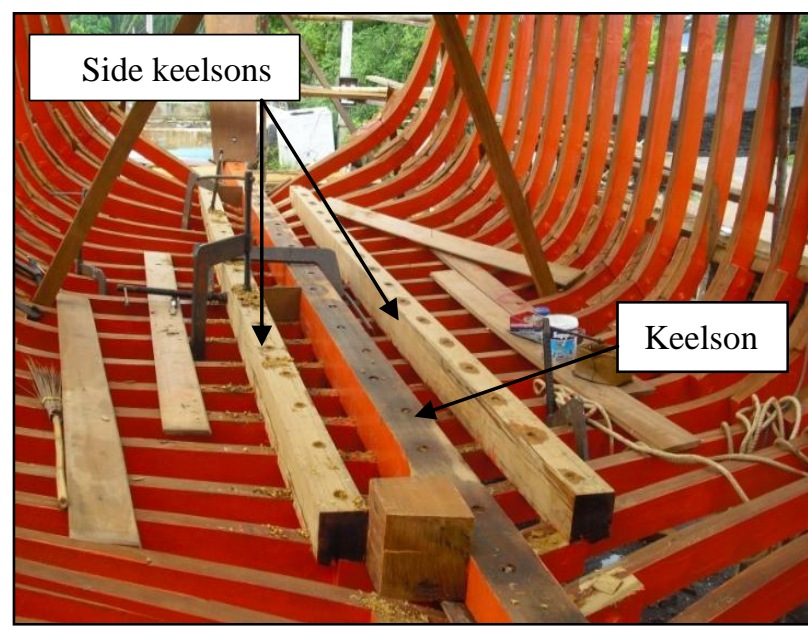

Fig. 10. Keelson and side keelsons.

\section{H. Placing the Girders or Stringers}

Girders or stringers are pieces of wood that are horizontally placed along the length of the fishing vessel in parallel with the keelson. A number of girders are used; the first girder is placed from the bottom upwards. Girders are placed apart from each other at regular intervals. The function of girders is to strengthen the vessel and support the frames or ribs (Fig. 11).

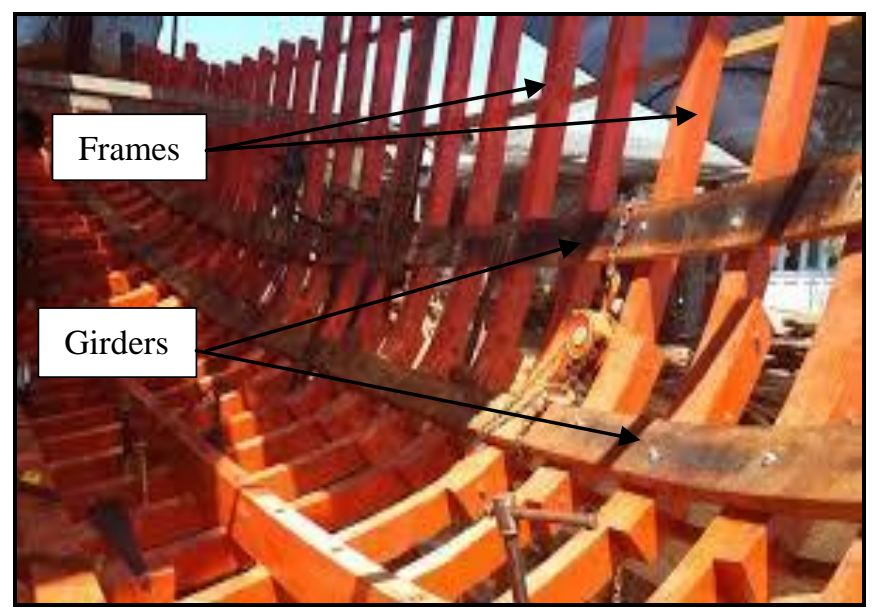

Fig. 11. Girders and frames.

\section{Planking the Hull}

Planking refers to the step in which each piece of wood is placed horizontally outside the vessel from the very bottom 
to the top of the vessel. Normally, the hull of a vessel is preferably made of padauk wood because of its durability. Planking the hull is performed according to the skeletons formed by an array of frames or ribs of the vessel. In the old days, to make the planking curve as designed, a pressure stove was used. The heat from the pressure stove made the plank bend or curve conforming to the vessel frames (Fig. 12) Planking the hull usually starts from the bottom, moving up to the top planking and the deck. The first piece of wood for planking the hull is called the garboard strake. While planking is being done, outside the hull, a hydrofoil is fastened on each side of the vessel. Similar to an aircraft wing in its appearance and function, the foil develops lift as it passes through the water. The hull is raised above the surface, and the drag caused by the vessel's contact with the water is thereby reduced.

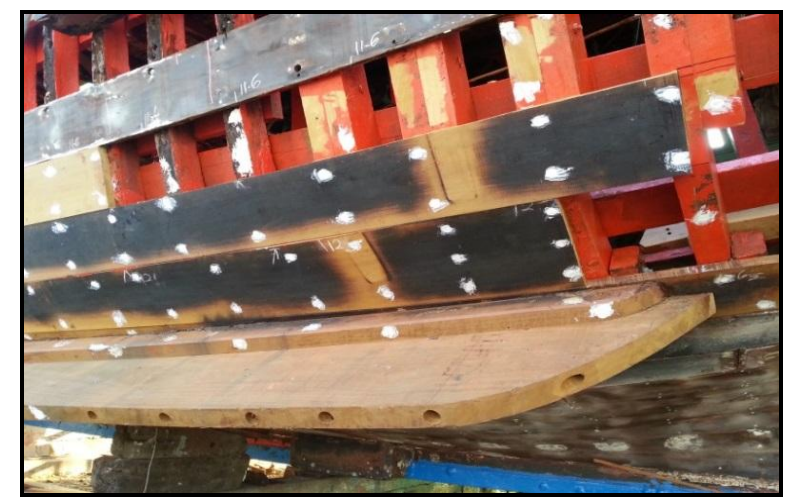

Fig. 12. Traces of a burn resulting from the heat from the pressure stove.

\section{J. Laying the Deck Beams}

Deck beams are pieces of wood placed across the vessel to support the fishing vessel deck. The deck beams are usually not straight but form a slight slope at each of the two ends, making the deck beams look like a tamarind pod. The slope of the two ends allows water on the deck to flow faster through freeing ports at the two sides of the vessel and to avoid creating ponds of water on the deck. When the deck beams are neatly placed at regular intervals, deck planking begins. Under the deck planking are a number of stanchions or pillars that are upright bars or posts in a vertical position to support the deck beams.

\section{K. Laying the Port Side and Starboard Side}

Port side and starboard side refer to two pieces of thick long wood on the left and right hand sides, respectively, of the vessel facing forward. Both pieces of wood are parallel to the last bilge planking. The port side and the starboard side are crucial parts of the vessel, holding all the frames of the fishing vessel from the very first one at the front to the last one at the back on each side of the vessel.

\section{Laying the Bulwark}

Bulwark is an extension of a vessel's port or starboard side which is above the level of the deck. In fact, this part is easy to spot because it is the area on which the name of the fishing vessel is written. Its function is to strengthen the vessel and also to serve other purposes including preventing the fishing net, fishing gear, and fish holds from slipping into the water. This part is traditionally painted white.
At this juncture, the construction of the fishing vessel is more or less completed, and the vessel is ready to be launched into water. For safety purposes, the vessel should be as light as possible. The construction of other parts of the vessel can be continued after the launch, including the building of the deckhouse, crow's nest, mast, fairlead or fairleader or chock, and hatch coaming.

A deckhouse or superstructure is the largest a construction raised from the deck, consisting of a number of small rooms with roofs to protect the crew from the rain and the sun. These rooms are living quarters or berths for the crew members. Originally, the deckhouse of a vessel consisted of only one deck. However, due to an increasing number in the crew members, one deck is far from enough. As a result, a multi-deck deckhouse is increasingly more common. Typically, the deckhouse occupies the mid-ship position.

In addition to the deckhouse, inside the hull, are a number of fish holds, refrigerated quarters or freezing rooms that occupy a substantial area of the vessel hull. The main purpose of freezing rooms is to keep and maintain the freshness of the catch. The number of freezing rooms, however, depends on the size of the fishing vessel.

Other less significant structures include a fairlead, crow's nest, and hatch coaming (Fig. 13). To elaborate, a fairlead is a device to guide a rope or cable or to stop it from moving laterally. On the upper part of the mast of a vessel is a crow's nest, a structure that is used as a lookout point. Under the deck are a number of rooms for storing a catch. In order to prevent water from flowing into these rooms under the deck, hatch coaming or a raised frame around a hatch is built. In short, all these structures are built to accommodate other activities related to fishing which are performed on the deck.

The construction of the fishing vessels cannot be accomplished by only the shipwrights but also by other parties including painters, caulkers, and welders. For instance, caulkers can start their job after planking is completed. They prepare a mixture of caulk and force it into the grooves between the planking. This step is to make sure the gap between planks of wood is filled, not allowing the sea water to seep inside the vessel. A welder is responsible for securing the rudder and the propeller at the stern of the vessel. The propeller is usually made of brass, with 3 or 4 blades depending on the engine power and the size of the vessel.

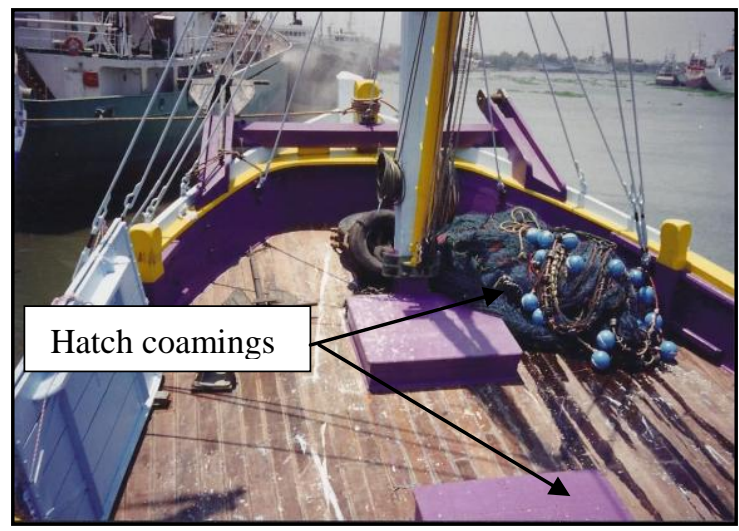

Fig. 13. On the deck: Hatch coamings.

When the shipwrights and the caulkers have completed their job, the painters will give a finishing touch to the vessel. 
That is, they are responsible for painting the entire fishing vessel, be it the part under or above the water, in different colors. The part under the water is usually coated with a special paint that prevents shipworms from boring the wood. The vessel hull can be of any color, depending on the vessel owner. However, the port and starboard sides are usually painted bright orange. When painting is completed, the vessel is ready to be launched into the water which is typically accompanied by a ritual to pay respect to the boat Goddess.

\section{SAMUt SAKhon Vessels' UniQue FeAtures}

The ten masters interviewed congruently acknowledged that the guru of this local wisdom at Samut Sakhon is a Chinese Hainanese, Mr. Kheng Hiang Sae Wang, who migrated to Thailand about 100 years ago. He established his own small dockyard with a number of workers under him. His business expanded over the years, attracting a number of people who were interested in carpentry and woodwork. His dockyard thus attained the status of "a school of fishing vessel building." The ten masters interviewed in this study were apprentices at this shipyard to accumulate knowledge. Eventually, they successfully established themselves to be shipwrights and set up their own fishing vessel businesses.

Some of the ten masters moved from one shipyard to another to acquire new and different techniques, contributing to their own unique style or signature of vessel building. Their individual styles can be displayed through, for example, the deck house with elaborated corridors and the port side and the starboard side of two layers each. Some focused on the form of the vessel and the others focused on the strength of the vessel. Whatever it is, due to these delicate details reflecting individual techniques and styles of building, these vessels can be recognized by these masters from a distance.

Over the years, the styles and techniques of building a vessel have been improved and becoming more embellished. The tools have also changed. For instance, manual planes and pressure stoves have been replaced by electric saws and gas stoves. Laborers who carried planks of wood up to the deck, frequently causing injuries, have been replaced by cranes. Time spent on building a vessel has shrunk from a year to only a few months. Despite all these changes that have taken place, one thing that never changes is the love and passion for these vessels from Samut Sakhon residents and shipwrights (Fig. 14).

Samut Sakhon wooden fishing vessels are different from those constructed in other provinces. Their outstanding and distinguishing features are twofold. First, only high quality wood is used to build Samut Sakhon wooden fishing vessels. As mentioned earlier, certain woods have particular characteristics and are suitable for certain parts of the vessel. Despite the scarcity of certain wood, Samut Sakhon shipwrights would never compromise using lower quality wood. In fact, only hopea odorato wood and padauk wood are used, contributing to the remarkable strength and durability of the vessel. In contrast to Samut Sakhon vessel builders, other shipwrights in some areas use mixed types of wood to build the vessels, regardless the properties of the wood. As a result, the vessels constructed are not strong, nor of high quality. Second, the structure of Samut Sakhon wooden fishing vessels is graceful and proportionated. For example, the port and the starboard sides are elegantly curved

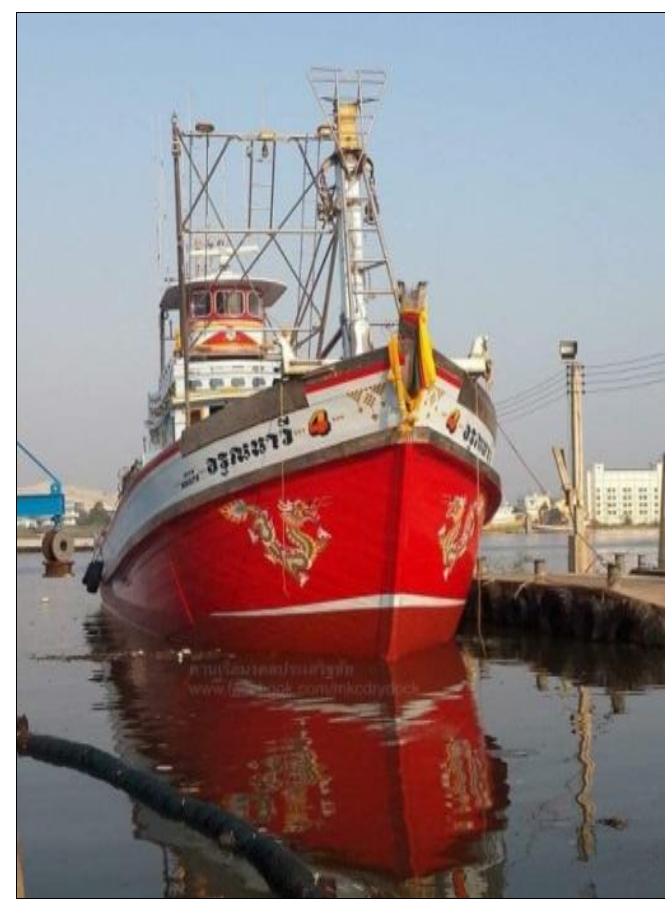

Fig. 14. A typical Samut Sakhon wooden fishing vessel.

forming a line that controls the entire formation of the vessel. Therefore, when sailing in the water, the vessel looks graceful. These two features contribute to the uniqueness of Samut Sakhon wooden fishing vessels, the builders' pride. In short, Samut Sakhon fishing vessels not only perform their role as a vehicle but also demonstrate the shipwrights' ability to manipulate the material characteristics in such a manner compatible with the nature of the sea.

\section{FACTORS IMPACTING THE VESSEL INDUSTRY}

After about 100 years since wooden fishing vessel building was established in Samut Sakhon, this business has been impacted by several factors and finally came to an end about a decade ago. The hardship of this job, the scarcity of materials, advanced technology, fluctuating oil prices, and other geographical factors, were contributing factors.

Being a fishing vessel builder is an arduous task because the shipwrights work outdoors all the time, rain or shine. Dust and noise generated by wood sawing and operating machines have earned this job a negative image. None of the descendants of the ten masters interviewed is interested in continuing the tradition of the family - being a vessel builder. The shortage emerges not only in the smaller number of builders but also in the number of laborers recruited to be crew members, when out at sea. Thai people do not want to be on the sea on fishing vessels because it means that they have to be far away from family members for a long period of time (weeks or months). Life on a fishing vessel is full of danger as well. The hardship encountered by the shipwrights and the vessel crew had a negative impact on the wooden fishing vessel construction business.

As shown, wood is the fundamental and of paramount 
importance in wooden fishing vessel building. As a result of the government's policy decades ago to discourage deforestation nation-wide, wood has become scarce. That is, the traditional belief in using hopea adorato wood and padauk wood for fishing vessel construction has begun to be impossible. The depletion of certain wood types also triggers shipwrights to look for a new material to build a vessel. The import of wood from neighboring countries is the only way to solve this problem. Due to the shortage of high quality wood and the need to use lower quality wood, wooden fishing vessels are not the same anymore.

With the introduction of advanced technology and development, wood is no longer the only possible material for building fishing vessels. Nowadays, fishing vessels made of iron have become ubiquitous. To these wooden fishing vessel builders, iron fishing vessels cannot and will not be graceful and beautiful; however, they functionally serve the purpose. In addition, while wooden fishing vessels need to be carefully maintained on a regular basis (e.g., repairing broken parts and painting the entire vessel on a yearly basis), iron fishing vessels are relatively much easier to take care of. In this regard, the masters argue that if a wooden fishing vessel is well maintained, it can last and serve the purpose for as long as 60 years. Unlike iron fishing vessels, after about 15 years or so, they are cut into pieces like junk.

The fishing vessel building industry also suffers from other factors, be they local or national. Locally, the floods in Samut Sakhon resulted from the national policy to use this province as an area for water irrigation to the Gulf of Thailand. The high level of water in the Tha Chin River thus flooded the area. To solve this environmental problem, a dam along the coast was constructed. This had an immediate impact on wooden fishing vessel building because a vessel partly completed in a shipyard could no longer be launched into the water. This indirectly means that this wooden fishing vessel building had to come to a stop.

For each fishing trip, a large quantity of oil is needed. It is known that the price of oil is unpredictable, fluctuating depending on the oil market price and other political situations in the world. Whenever the oil price rises, it simply means that the vessel owner is likely to lose a lot of money on oil costs. In addition, due to advancements in technology, fishing gear has been substantially improved, contributing to high yields of catch. Adversely, over a period of time, fish stocks worldwide have been on a decline. Moreover, Thai fishing vessels do not follow the international rules of fishing and use forbidden types of fishing gear. To retaliate, neighboring countries have begun to implement tough measures, reinforcing international laws. Many Thai fishing vessels have been capsized and/or confiscated under the accusation of invading other countries' waters. In addition, currently, the competition when selling fish hauls is tougher because of an increase in farm-raised fish and seafood imports in the market. Finally, vessel owners do not want to build new fishing vessels because of exceedingly high costs. Due to the absence of the demand for wooden fishing vessels, the shipwrights were forced to stop building them.

In short, because of the above mentioned factors - no demand for wooden fishing vessels, high cost of construction, the dam around the province, the termination of deforestation, the decline of fish stocks, the improvements in fishing gear and building technology, and increasing competition from farm-raised fish and seafood imports - fishing vessel construction in Samut Sakhon came to an end about 10 years ago.

\section{CONCLUSION}

The closure of individual shipyards not only leads to the end of this building business. In fact, the incident leads to a new chapter of fishing vessel building in Samut Sakhon.

As a common practice, wood fishing vessels need be in a dry dock for repair and maintenance purposes at least once a year. The fishing vessel building masters who are still strong and healthy decided to do the job of repairing broken parts of the vessels. However, in certain circumstances, repairing a vessel might not be worthwhile because the demand for more space for fishing holds and expanded freezing rooms to store a larger quantity of the catch is inevitable. Thus, expanding a vessel either vertically or horizontally rather than building a new one seems to be a reasonable and justified decision. For instance, additional freezing rooms are created by extending the existing keel, thus making the vessel generally longer. Or the sternpost is modified to accommodate the need for more space to work at the back of the vessel.

In conclusion, this study represents an attempt to record the knowledge regarding the local wisdom of Samut Sakhon Province - wooden fishing vessel construction. It is expected that the accounts will be valuable and beneficial for future generations. As demonstrated by this study, it is impossible to stop this traditional local wisdom from being replaced by modern technology. Therefore, it is indeed the matter of how much we can maintain and preserve local wisdom. The author sincerely hopes that this study serves the objective of recording, engraving, revitalizing, and disseminating the local wisdom of wooden fishing vessel construction.

\section{ACKNOWLEDGMENT}

The researcher would like to express heartfelt gratitude to a number of individuals who have contributed to the successful completion of this project: the interviewees who have willingly sacrificed their limited time providing useful pieces of information and Mr. Pramot Butsayamongkhon for his kind assistance and permission to take pictures of the wooden fishing vessels at his dockyard, allowing the researcher to better understand how the wooden fishing vessels at Samut Sakhon were constructed.

\section{REFERENCES}

[1] Information Technology and Communication Group, Samut Sakhon Governor's Office, City Hall, Floor 5, Mahachai, Mueang, Samut Sakhon 74000. (2014). Samut Sakhon Province. [Online]. Available: http://www.samutsakhon.go.th/en/aboutus.html

[2] T. Wiyaphorn. (2014). Samut Sakhon Province. [Online]. Available: http://www.samutsakhon.go.th/support40853/source/citizen.pdf

[3] List of Thai provinces by GPP. (2015). Office of the National Economic and Social Development Board. [Online]. Available: http://www.nesdb.go.th/Default.aspx?tabid=96

[4] C. Boyce and P. Neale. (2006). Conducting in-depth interview: A guide for designing and conducting in-depth interviews for evaluation input. [Online]. Available: http://www.pathfind.org/site/Doc Server/ m_e_tool_series_indepth_interviews.pdf?docID $=6301$ 
[5] F. Liu and S. Maitlis, "Nonparticipant observation," in Albert J. Mills, G. Durepos, \& E. Wiebe (Eds.), Encyclopedia of Case Study Research, 2010.

[6] D. W. Stewart, P. N. Shamdasani, and D. W. Rook, Focus Groups: Theory and Practices, $2^{\text {nd }}$ ed. Thousand Oaks, CA: SAGE, 1990.

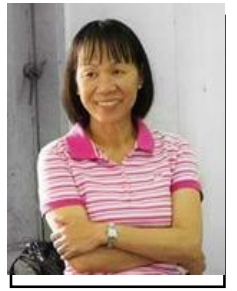

Budsaba Kanoksilapatham was born in Samu Sakhon province, Thailand. She completed her bachelor's degree in English (second class honors) at

Chulalongkorn University, Thailand. Later, she earned her master's degree in linguistics and English as a foreign language at Southern Illinois University at Carbondale and subsequently her doctoral degree in linguistics (concentration: applied linguistics) at
Georgetown University Washington DC, USA in 2003.

She is currently a professor at the English Department, Faculty of Arts, Silpakorn University, Nakhon Pathom, Thailand. Her most recent books are Pronunciation in Action and English Sociolinguistics at Work. Her research articles were published in international journals including English for Specific Purposes, The IEEE Transactions on Professional Communication, and 3L: The Southeast Asian Journal of English Language Studies.

Dr. Budsaba Kanoksilapatham has also served as a reviewer for a number of both national and international journals. 